\title{
Bacterial and fungal superinfections in critically ill patients with COVID-19
}

\author{
Matteo Bassetti ${ }^{1,2^{*}}$ (D) Marin H. Kollef ${ }^{3}$ and Jean-Francois Timsit ${ }^{4,5}$
}

(c) 2020 Springer-Verlag GmbH Germany, part of Springer Nature

Are critically ill patients with coronavirus disease 2019 (COVID-19) at high risk of bacterial and fungal superinfections developing on the top of the viral infection in the lung or in other body sites? And from which organisms? Answering these apparently simple questions could be far more difficult than expected, for at least three important reasons.

The first one is that the timing of development of superinfection (early or late) with respect to the intensive care unit (ICU) admission may have relevant clinical implications. Indeed, borrowing from experiences in other ICU populations it cannot be excluded a priori that early and late superinfections may be profoundly different in terms of risk [1,2]. However, early and late superinfections have been frequently lumped together in the currently available literature on COVID-19 patients, making it difficult to firmly grasp their separate risks [3, 4]. The second reason is that the high case fatality of the viral disease per se may be an important competing risk for the development of late superinfection, which may lead to an unintended underestimation of the risk of superinfection at the bedside of alive patients. The third reason specifically involves invasive aspergillosis, for which the current absence of a standardized definition for non-proven disease in non-neutropenic critically ill patients may preclude a reliable risk assessment also in COVID-19 patients [5]. In the next few paragraphs, we briefly discuss each of these three intertwined, important issues.

\footnotetext{
*Correspondence: matteo.bassetti@unige.it

${ }^{1}$ Clinica Malattie Infettive, Ospedale Policlinico San Martino-IRCCS, L.go R. Benzi 10, 16132 Genoa, Italy
}

Full author information is available at the end of the article

\section{Early and late superinfections}

The prevalence of laboratory-confirmed bacterial superinfection in critically ill COVID-19 patients in ICU could be around 14\% (95\% confidence interval 5-26\%) according to a recent meta-analysis [3]. However, in most included studies there was no distinction between early and late infections. Although on the surface this may appear mere semantics, in reality such a distinction has important implications for antimicrobial prescribing in real life. Indeed, should it be proven that most superinfections in critically ill COVID-19 patients develop late and not early during the ICU stay (or during exposure to the hospital environment), the widespread attitude toward universally prescribing empirical antibacterials in critically ill COVID-19 patients since ICU/hospital admission could no longer be supported [4]. This is in line with a recent observational cohort of 78 critically ill COVID-19 patients, in whom the cumulative risk of developing a bloodstream infection (BSI) after at least $48 \mathrm{~h}$ from ICU admission was estimated to be of almost $25 \%$ at 15 days after ICU admission [6]. Compared with the meta-analytic results reported above and notwithstanding the important limitation of the small sample size, such results seem to suggest that most were late superinfections, which is in line with the low prevalence of superinfection at hospital admission registered in other experiences in COVID-19 patients [7].

\section{Superinfection-free COVID-19 case fatality as a competing risk}

The basic, intuitive rule is the following: if a critically ill COVID-19 patient dies early during ICU stay without superinfection, he/she can no longer develop a late superinfection. Although this is obvious, it should be noted that the very same patient usually remains in the denominator for estimating the prevalence of superinfection in the entire population of critically ill COVID-19

\section{国 Springer}


patients $[3,4]$. In turn, if the calculated prevalence is inadvertently perceived as the risk of late superinfection in the subgroup of patients still alive after the first days of ICU stay, this could lead to an underestimation of the risk of late superinfection at their bedside. Given the high case fatality of COVID-19 in critically ill patients ( $>25 \%)$ [8], it cannot be excluded that the magnitude of this potential underestimation could be remarkable.

\section{COVID-19-associated pulmonary aspergillosis}

More than 30 cases of COVID-19-associated pulmonary aspergillosis (CAPA) have been published to date [9]. Overall, the possible development of invasive pulmonary aspergillosis in some critically ill COVID-19 patients is somewhat expected, considering the following, likely cumulative risk factors: (1) the epithelial lung damage caused by either the virus or the dysregulated host response; (2) the frequent use of corticosteroids [10]; (3) a possible similarity with influenza-associated invasive aspergillosis (IAPA) [11]. However, some clinically relevant differences between IAPA and CAPA have been described. For example, it has been hypothesized that the different distribution in the airways of the host cells receptors used by SARS-CoV-2 and influenza viruses may imply a different risk of invasive Aspergillus tracheobronchitis (i.e., lower for COVID-19 than influenza patients). In addition, different effects of the two different viruses on the host immune response could possibly explain a usually worse disease progression in IAPA than in CAPA. Finally, the diagnostic performance of fungal

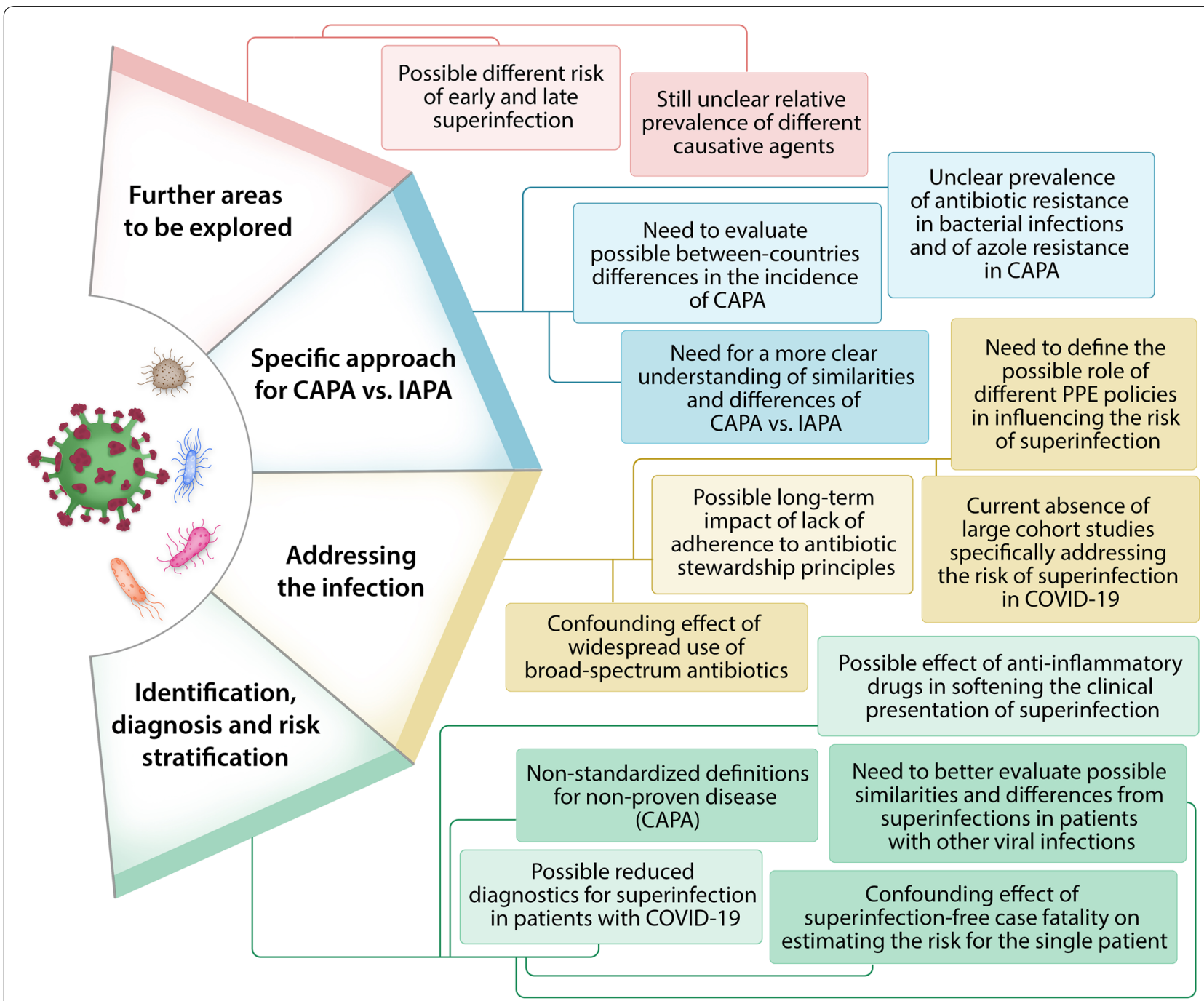

Fig. 1 Building blocks of the current uncertainty in estimating the true risk of bacterial and fungal superinfections in COVID-19 patients. No differences in the relative importance of the various represented blocks can be firmly defined at the present time. COVID-19 coronavirus disease 2019 , CAPA COVID-19-associated pulmonary aspergillosis, IAPA influenza-associated invasive aspergillosis, PPE protective personal equipment 
antigens tests could be different (e.g., lower sensitivity of serum galactomannan in CAPA than in IAPA) [11, 12]. Very importantly, all of this also stands against the backdrop of a lack of a standardization in the definition of non-proven invasive aspergillosis in non-neutropenic critically ill patients, which itself contribute in further fueling the uncertainty regarding the true prevalence of CAPA. While waiting for the results of ongoing projects to improve the definition of invasive aspergillosis in ICU patients [5, 13], the most reliable definition for non-proven CAPA remains that of putative invasive pulmonary aspergillosis according to the AspICU algorithm [14]. However, although of important help, it is of note that this algorithm requires a positive airways culture for Aspergillus, and respiratory cultures were shown to have low sensitivity when tested against a reliable reference standard (histology/autopsy) [15].

In conclusion, the true prevalence of bacterial and fungal superinfections in critically ill COVID-19 patients still remains elusive. In our opinion, a possible underestimation of the risk of late superinfection may occur at the bedside of ICU patients with COVID-19, for the reasons summarized in Fig. 1. Notably, all these confounding factors also hamper a clear identification of the most frequent bacteria associated with superinfection, with either Gram-negative or Gram-positive organisms having alternatively deemed as the major culprit [3, 4]. Further dedicated investigation is necessary to better understand the true risk and the disease spectrum of superinfection in critically ill patients with COVID-19, with the ultimate aim of improving their management and outcomes.

\section{Author details \\ ${ }^{1}$ Clinica Malattie Infettive, Ospedale Policlinico San Martino-IRCCS, L.go R. Benzi 10, 16132 Genoa, Italy. ${ }^{2}$ Department of Health Sciences, University of Genoa, Genoa, Italy. ${ }^{3}$ Division of Pulmonary and Critical Care Medicine, Washington University School of Medicine, St. Louis, MO, USA. ${ }^{4}$ Medical and Infectious Diseases Intensive Care Unit, Bichat-Claude Bernard University Hospital, Paris, France. ${ }^{5}$ INSERM IAME, U1137, Team DesCID, Paris, France.}

\begin{abstract}
Acknowledgements
Outside the submitted work, MB has received funding for scientific advisory boards, travel and speaker honoraria from Angelini, Astellas, AstraZeneca, Basilea, Bayer, BioMérieux, Cidara, Correvio, Cubist, Menarini, Molteni, MSD, Nabriva, Paratek, Pfizer, Roche, Shionogi, Tetraphase, Thermo Fisher, and The Medicine Company. Outside the submitted work, JFT has received fund for advisory boards from Beckton-Dickinson, Gilead, Pfizer, MSD, Nabriva, Medimmune, Paratek, Astellas, Bayer and received fees for giving lectures in symposia for MSD, Pfizer, BioMérieux. JFT research unit received fund for research grants from MSD, Pfizer, and 3M. MHK is supported by the Barnes-Jewish Hospital Foundation.
\end{abstract}

\section{Funding}

None.

\section{Compliance with ethical standards}

\section{Conflict of interest}

None.

\section{Publisher's Note}

Springer Nature remains neutral with regard to jurisdictional claims in published maps and institutional affiliations.

Received: 8 July 2020 Accepted: 14 August 2020

Published online: 9 September 2020

\section{References}

1. Ibn Saied W, Souweine B, Garrouste-Orgeas M, Ruckly S, Darmon M, Bailly S, Cohen Y, Azoulay E, Schwebel C, Radjou A, Kallel H, Adrie C, Dumenil AS, Argaud L, Marcotte G, Jamali S, Papazian L, Goldgran-Toledano D, Bouadma L, Timsit JF, Group Os (2017) Respective impact of implementation of prevention strategies, colonization with multiresistant bacteria and antimicrobial use on the risk of early- and late-onset VAP: an analysis of the OUTCOMEREA network. PLoS One 12:e0187791

2. Micek ST, Hampton N, Kollef M (2018) Risk factors and outcomes for ineffective empiric treatment of sepsis caused by gram-negative pathogens: stratification by onset of infection. Antimicrob Agents Chemother 62(1):e01577-17

3. Lansbury L, Lim B, Baskaran V, Lim WS (2020) Co-infections in people with COVID-19: a systematic review and meta-analysis. J Infect 81 (2):266-275

4. Rawson TM, Moore LSP, Zhu N, Ranganathan N, Skolimowska K, Gilchrist M, Satta G, Cooke G, Holmes A (2020) Bacterial and fungal co-infection in individuals with coronavirus: a rapid review to support COVID-19 antimicrobial prescribing. Clin Infect Dis. https://doi.org/10.1093/cid/ciaa530

5. Bassetti M, Giacobbe DR, Grecchi C, Rebuffi C, Zuccaro V, Scudeller L, Investigators F (2020) Performance of existing definitions and tests for the diagnosis of invasive aspergillosis in critically ill, adult patients: a systematic review with qualitative evidence synthesis. J Infect 81:131-146

6. Giacobbe DR, Battaglini D, Ball L, Brunetti I, Bruzzone B, Codda G, Crea F, De Maria A, Dentone C, Di Biagio A, Icardi G, Magnasco L, Marchese A, Mikulska M, Orsi A, Patroniti N, Robba C, Signori A, Taramasso L, Vena A, Pelosi P, Bassetti M (2020) Bloodstream infections in critically ill patients with COVID-19. Eur J Clin Investig. https://doi.org/10.1111/eci.13319

7. Hughes S, Troise O, Donaldson H, Mughal N, Moore LS (2020) Bacterial and fungal coinfection among hospitalised patients with COVID-19: a retrospective cohort study in a UK secondary care setting. Clin Microbiol Infect. https://doi.org/10.1016/j.cmi.2020.06.025

8. Grasselli G, Zangrillo A, Zanella A, Antonelli M, Cabrini L, Castelli A, Cereda D, Coluccello A, Foti G, Fumagalli R, lotti G, Latronico N, Lorini L, Merler S, Natalini G, Piatti A, Ranieri MV, Scandroglio AM, Storti E, Cecconi M, Pesenti A, Network C-LI, Nailescu A, Corona A, Zangrillo A, Protti A, Albertin A, Forastieri Molinari A, Lombardo A, Pezzi A, Benini A, Scandroglio AM, Malara A, Castelli A, Coluccello A, Micucci A, Pesenti A, Sala A, Alborghetti A, Antonini B, Capra C, Troiano C, Roscitano C, Radrizzani D, Chiumello D, Coppini D, Guzzon D, Costantini E, Malpetti E, Zoia E, Catena E, Agosteo E, Barbara E, Beretta E, Boselli E, Storti E, Harizay F, Della Mura F, Lorini FL, Donato Sigurta F, Marino F, Mojoli F, Rasulo F, Grasselli G, Casella G, De Filippi G, Castelli G, Aldegheri G, Gallioli G, Lotti G, Albano G, Landoni G, Marino G, Vitale G, Battista Perego G, Evasi G, Citerio G, Foti G, Natalini G, Merli G, Sforzini I, Bianciardi L, Carnevale L, Grazioli L, Cabrini L, Guatteri L, Salvi L, Dei Poli M, Galletti M, Gemma M, Ranucci M, Riccio M, Borelli M, Zambon M, Subert M, Cecconi M, Mazzoni MG, Raimondi M, Panigada M, Belliato M, Bronzini N, Latronico N, Petrucci N, Belgiorno N, Tagliabue P, Cortellazzi P, Gnesin P, Grosso P, Gritti P, Perazzo P, Severgnini P, Ruggeri P, Sebastiano P, Covello RD, Fernandez-Olmos R, Fumagalli R, Keim R, Rona R, Valsecchi R, Cattaneo S, Colombo S, Cirri S, Bonazzi S, Greco S, Muttini S, Langer T, Alaimo V, Viola U (2020) Baseline characteristics and outcomes of 1591 patients infected with SARS-CoV-2 admitted to ICUs of the Lombardy Region. Italy. JAMA 323(16):1574-1581

9. Arastehfar A, Carvalho A, van de Veerdonk FL, Jenks JD, Koehler P, Krause R, Cornely OA, Perlin DS, Lass-Flörl C, Hoenigl M (2020) COVID-19 Associated pulmonary Aspergillosis (CAPA)-from immunology to treatment. J Fungi (Basel, Switz) 6(2):91

10. Horby P, Lim WS, Emberson J, Mafham M, Bell J, Linsell L, Staplin N, Brightling C, Ustianowski A, Elmahi E, Prudon B, Green C, Felton T, Chadwick 
D, Rege K, Fegan C, Chappell LC, Faust SN, Jaki T, Jeffery K, Montgomery A, Rowan K, Juszczak E, Baillie JK, Haynes R, Landray MJ (2020) Effect of dexamethasone in hospitalized patients with COVID-19: preliminary report. N Engl J Med. https://doi.org/10.1056/NEJMoa2021436

11. Verweij PE, Rijnders BJA, Bruggemann RJM, Azoulay E, Bassetti M, Blot S, Calandra T, Clancy CJ, Cornely OA, Chiller T, Depuydt P, Giacobbe DR, Janssen NAF, Kullberg BJ, Lagrou K, Lass-Florl C, Lewis RE, Liu PW, Lortholary O, Maertens J, Martin-Loeches I, Nguyen MH, Patterson TF, Rogers TR, Schouten JA, Spriet I, Vanderbeke L, Wauters J, van de Veerdonk FL (2020) Review of influenza-associated pulmonary aspergillosis in ICU patients and proposal for a case definition: an expert opinion. Intensive Care Med 46:1524-1535

12. Verweij PE, Gangneux J-P, Bassetti M, Brüggemann RJM, Cornely OA, Koehler P, Lass-Flörl C, van de Veerdonk FL, Chakrabarti A, Hoenigl M (2020) Diagnosing COVID-19-associated pulmonary aspergillosis. Lancet Microbe 1:e53-e55

13. Bassetti M, Scudeller L, Giacobbe DR, Lamoth F, Righi E, Zuccaro V, Grecchi C, Rebuffi C, Akova M, Alastruey-Izquierdo A, Arikan-Akdagli S, Azoulay E, Blot SI, Cornely OA, Lass-Florl C, Koehler P, Cuenca-Estrella M, de
Lange DW, De Rosa FG, De Waele JJ, Dimopoulos G, Garnacho-Montero J, Hoenigl M, Kanj SS, Maertens J, Martin-Loeches I, Munoz P, Kullberg BJ, Agvald-Ohman C, Poulakou G, Rello J, Sanguinetti M, Taccone FS, Timsit JF, Torres A, Vazquez JA, Calandra T, From the Study Group for Infections in Critically III P, The Fungal Infection Study Group of the European Society of Clinical M, Infectious D, European Society of Intensive Care M, European Confederation of Medical M, Mycoses Study Group E, Research C (2019) Developing definitions for invasive fungal diseases in critically ill adult patients in intensive care units. Protocol of the FUNgal infections definitions in ICU patients (FUNDICU) project. Mycoses 62:310-319

14. Blot SI, Taccone FS, Van den Abeele AM, Bulpa P, Meersseman W, Brusselaers N, Dimopoulos G, Paiva JA, Misset B, Rello J, Vandewoude K, Vogelaers D, Asp ICUSI (2012) A clinical algorithm to diagnose invasive pulmonary aspergillosis in critically ill patients. Am J Respir Crit Care Med 186:56-64

15. Meersseman W, Lagrou K, Maertens J, Wilmer A, Hermans G, Vanderschueren S, Spriet I, Verbeken E, Van Wijngaerden E (2008) Galactomannan in bronchoalveolar lavage fluid: a tool for diagnosing aspergillosis in intensive care unit patients. Am J Respir Crit Care Med 177:27-34 